\title{
Effects of Talaromyces purpureogenus on Cucumber Growth Promotion and Its Mechanism
}

\author{
Zhao $\mathrm{L}^{1 *}$, Zhao $\mathrm{W}^{1,2}$ and Deng $\mathrm{H}^{2}$ \\ ${ }^{1}$ College of Life Science, Shandong Normal University, \\ Jinan, China \\ ${ }^{2}$ Institute of Agricultural Resources and Regional \\ Planning, Chinese Academy of Agricultural Sciences, \\ Beijing, China \\ *Corresponding author: Zhao L, College of Life \\ Science, Shandong Normal University, No.88 Wenhua \\ East Road, Jinan, China
}

Received: April 30, 2021; Accepted: May 22, 2021; Published: May 29, 2021

\begin{abstract}
Some fungi may promote plant growth by production of siderophores, Indole Acetic Acid (IAA) and phosphorus dissolving capability. In this study, eight fungi were isolated from the mushroom substrate, and their siderophores production, IAA production and phosphorus dissolving traits were determined. Although there was no significant difference in IAA production among the eight fungi, but the strain M13026-2 was a fungus with strong growth promoting traits compared with other seven fungi. In order to study the correlation between the growth promoting effect of cucumber pot culture and the above three traits, five fungi with different strength of traits were tested in pot. As a result, M130262 which was identified as Talaromyces purpureogenus could significantly improve the growth parameters of cucumber seedlings, and could colonize in the rhizosphere soil and the tissue of cucumber stably. All the results suggested that the most relevant to their ability to promote plant growth is the trait of phosphorus dissolving, followed by siderophores production. The results of this study will provide scientific basis for the efficient selection and identification of a large number of fungi resources with the function of promoting plant growth, and reveal the good application potential of $T$. purpureogenus in agriculture fields.
\end{abstract}

Keywords: Siderophores; Indole acetic acid; Phosphorus dissolving; Cucumber growth promotion; Talaromyces purpureogenus; Colonization

\section{Introduction}

Due to the low bioavailability of micronutrients in soil, chemical fertilizers are needed to increase soluble elements for plant absorption and utilization to increase crop yields, which leads to soil hardening and nitrate pollution, and ultimately soil fertility decline [1]. Microorganisms can improve the ability of resistance to stress by interacting with plants.

The results showed that microorganisms can secrete siderophores or $\mathrm{Fe}^{3+}$ reductase to convert insoluble high iron oxide into the form of $\mathrm{Fe}^{2+}$ that can be directly absorbed and utilized by plants under the condition of iron deficiency [2,3]. In addition, some rhizosphere fungi such as Trichoderma asperellum can regulate endogenous hormones and secondary metabolites of plants to promote plant growth by producing IAA $[4,5]$. Phosphorus is an essential nutrient with low bioavailability for plant growth in soil, the use of phosphorus dissolving fungi has become an eco-friendly strategy to increase the bioavailability of this nutrient [6]. On the other hand, Phosphorus Solubilization Fungi (PSF) can increase available phosphorus in the environment by excreting organic acids or phosphatases $[7,8]$. PSF have been reported as Arbuscular mycorrhiza, Aspergillus, Penicillium, Talaromyces, Trichoderma and some yeasts [9-11]. Talaromyces fungi has good phosphorus dissolving effect, application of Talaromyces flavus in soil promoted the growth of wheat, tomato, cucumber, cotton and garlic [12-14]; application of Talaromyces wortmannii in soil promoted the growth of Arabidopsis thaliana, Nicotiana benthamiana, Cucumis sativus etc. [15]. In recent years, studies on the growth promoting effect of Trichoderma have been relatively mature. By using cucumber as biological indicator plant,
Trichoderma biofertilizer significantly improved the germination rate and growth parameters of cucumber $[4,16,17]$. Therefore, the application of beneficial fungi in agriculture not only promotes the growth of crops, but also reduces the utilization rate of chemical fertilizer.

Beneficial fungi include biocontrol fungi and Plant Growth Promoting Fungi (PGPF) [18]. Because most of the researchers focus on the screening of fungi with biocontrol and growth promoting effects under biotic or abiotic stress, some fungi with growth promoting function on crops are easy to be ignored under non stress conditions. The beneficial fungi can be screened out through the measurement of plant growth promoting traits, such as siderophores production, IAA production, and phosphorus dissolving ability $[19,20]$.

The strains contaminated with edible fungi with the characteristics of fast growth on the mushroom substrate made of the plant residues, which may have plant growth promoting effect under non stress conditions. We isolated eight strains to determine their plant growth promoting traits, and there are seven Trichoderma strains and one Talaromyces strain. Among these tested fungi, five strains with different strength of traits and high spore yield were selected for pot experiment to measure the growth indexes of cucumber seedlings. The purpose of this study is to preliminarily explore whether there is a corresponding relationship between the plant growth promoting effect of fungi and their traits of siderophores production, IAA production, and phosphorus dissolving. At the same time, the fungus with significant growth promoting effect on cucumber was screened out and its colonization ability was measured to evaluate its application potential in soil. 


\section{Materials and Methods}

\section{Fungal strains}

The tested fungi in this study were isolated from the mushroom substrate in the previous work of our laboratory, identified to the genus through rDNA ITS sequencing and analysis.

\section{Growth promoting traits of the eight fungi}

Siderophore production: The spores of eight tested fungi were washed on a PDA plate with sterile water containing two drops of Tween 80 to prevent the spores from forming clumps [21], which were counted with a hemocytometer and diluted into the spore suspension with the concentration of $10^{7}\left(\mathrm{CFU} \mathrm{ml} l^{-1}\right)$. Finally, a volume of $1 \mathrm{ml}$ spore suspension was added into $100 \mathrm{ml}$ iron deficiency liquid nutrient medium in a flask, which was cultured and agitated at $180 \mathrm{r}$ $\min ^{-1}$ for 5 days at $28^{\circ} \mathrm{C}$. The content of siderophore was determined by a CAS blue test as below [22]. Siderophore content was measured every $24 \mathrm{~h}$ for five consecutive times.

Siderophore Content $(\%)=[(A r-A s) / A r] \times 100[23]$.

IAA production: A volume of $1 \mathrm{ml}$ spore suspension of eight tested fungi was inoculated in IAA liquid medium supplemented with L-tryptophan at $100 \mathrm{mg} \mathrm{L}^{-1}$, then cultured and agitated at 180 $\mathrm{r} \min ^{-1}$ for 5 days at $28^{\circ} \mathrm{C}$. The content of IAA was determined by Salkowski reagent [24]. The IAA purified product was used to make standard curve to calculate IAA content in fermentation broth. The IAA content was measured every $24 \mathrm{~h}$ for five consecutive times.

Inorganic phosphorus dissolving: A volume of $1 \mathrm{ml}$ spore suspension of eight tested fungi was inoculated in inorganic phosphorus solution medium containing $0.5 \%$ Tricalcium Phosphate (TCP). Then the ammonium vanadate-molybdate spectrophotometry method was used to detect available phosphorus in fermentation broth [25]. The phosphorus standard solution instead of supernatant were used to make a standard curve. According to the standard curve, available phosphorus content was calculated. The available phosphorus content was measured every $24 \mathrm{~h}$ for five consecutive times.

Organic phosphorus dissolving: Calcium phytate was used to replace the TCP in the phosphate solution medium to prepare the solid medium. The colonies of eight tested fungi was picked using a sterile toothpick and inoculated at the center of the solid medium plate. Finally, the diameter (D) of the appearing dissolved phosphate ring and the diameter (d) of the colony were measured. The ability to dissolve organic phosphorus was determined by D/d [26]

Screening for plant growth promoting fungus (PGPF): The cucumber variety used in the experiment was Zhongnong 16 from China vegetable seed technology Co., LTD. (Beijing) and the soil was the farmland soil of Shunyi, Beijing. Cucumber seeds were immersed in $70 \%$ alcohol for $2 \mathrm{~min}$ and $2 \%$ sodium hypochlorite for $2 \mathrm{~min}$ for disinfection, rinsed with sterile water for three times [27], and then put in a petri dish containing a small amount of sterile water for germination at $25^{\circ} \mathrm{C}$. The soil was sterilized at $120^{\circ} \mathrm{C}$, for $1 \mathrm{~h}$ by 3 times.

Five days after germination, cucumber seedlings were selected with consistent growth for transplanting. In the pot experiment, the spore amount of strains in the soil was about $10^{6} \mathrm{CFU} \mathrm{g}{ }^{-1}$, therefore, five strains with high spore yield were selected from eight tested fungi for pot experiment. Before transplanting, the farmland soil evenly mixed with spore suspension, adding aseptic water equal to spore suspension as control. The control group and treatment group were 15 cucumber seedlings respectively, repeated for three times. The spore suspension was replenished after 15 days to prevent spore infiltration to the bottom of the cup [28]. After 30 days, the growth parameters of cucumber were measured, in order to reduce the workload, root scanning was carried out only in the treatment group that had a significant effect on plant root growth to measure root length and root area.

Identification of M13026-2: The strain M13026-2 was cultured on PDA plate at $28^{\circ} \mathrm{C}$ for five days for morphological observation, and then the genomic DNA was extracted from it. The primers ITS4 and ITS5 were used to amplify partial nucleotide sequences in the internal transcribed spacer of the nuclear rRNA gene (rDNA ITS) [29]; Bt2a and Bt2b were used to amplify the beta tubulin gene (TUB) [30]; cmdAD1 and cmdQ1 were used to amplify the partial calmodulin gene (CaM) [31]. PCR was performed in a $50 \mu \mathrm{l}$ amplification system containing $18 \mu \mathrm{l} \mathrm{ddH_{2 }}$ O, $25 \mu \mathrm{l}$ Taq PCR StarMix, $1 \mu$ forward primer, $1 \mu \mathrm{l}$ reverse primer, $5 \mu \mathrm{l}$ fungal DNA. The reaction procedure was: $94^{\circ} \mathrm{C}$ initial denaturation for $3 \mathrm{~min}$, followed by 35 cycles $\left(94^{\circ} \mathrm{C}\right.$ denaturation for $35 \mathrm{~s}, 52^{\circ} \mathrm{C}$ annealing for $1 \mathrm{~min}, 72^{\circ} \mathrm{C}$ extension for $90 \mathrm{~s}$ ), and $72^{\circ} \mathrm{C}$ extension for $10 \mathrm{~min}$. PCR products were sent to BioLeXin company for sequencing. BLASTn search was used to analyze the sequence of M13026-2 in GenBank to preliminarily determine its genus and probable species name. Phylogenetic analysis of M13026-2 and its related species was carried out using MEGA 6.0 software [32].

\section{Colonization ability of PGPF (Talaromyces purpureogens, M13026-2)}

In cucumber rhizosphere: After transplanting cucumber seedlings as described above, rhizosphere soil samples were collected on days 14, 21 and 28. First, three cucumber plants treated with PGPF were randomly selected and gently pulled out of the soil. The loose soil on the root system was shaken off, and the residual soil particles at the root were completely removed by washing in a triangular bottle containing sterile water [33]. Then the PGPF in rhizosphere soil samples was counted by the gradient dilution method.

After counting, a colony was randomly selected from each concentration plate and transferred to a new PDA medium for culture, and DNA was extracted and rDNA ITS region was sequenced for verification.

In cucumber tissue: In this study, the Isolation Frequency (IF) of PGPF was calculated by tissue culture method, and its colonization ability in cucumber tissue was evaluated [34]. Three cucumber seedlings were randomly selected after 25 days of transplanting, washed with water and separated from roots, stems and leaves, and then soaked in $75 \%$ alcohol for $1 \mathrm{~min}, 3.25 \%$ sodium hypochlorite for $3 \mathrm{~min}$, and $75 \%$ alcohol for $30 \mathrm{~s}$, respectively [35]. Next, roots, stems and leaves were cut into $5 \mathrm{~mm}$ diameter pieces with aseptic scissors and cultured in PDA plates containing ampicillin $\left(50 \mathrm{mg} \mathrm{L}^{-1}\right)$. Five tissue blocks were placed in each plate, while cucumber seedlings without inoculation was used as control. After four days, the tissue fragments with PGPF colony were counted. After counting, a colony 

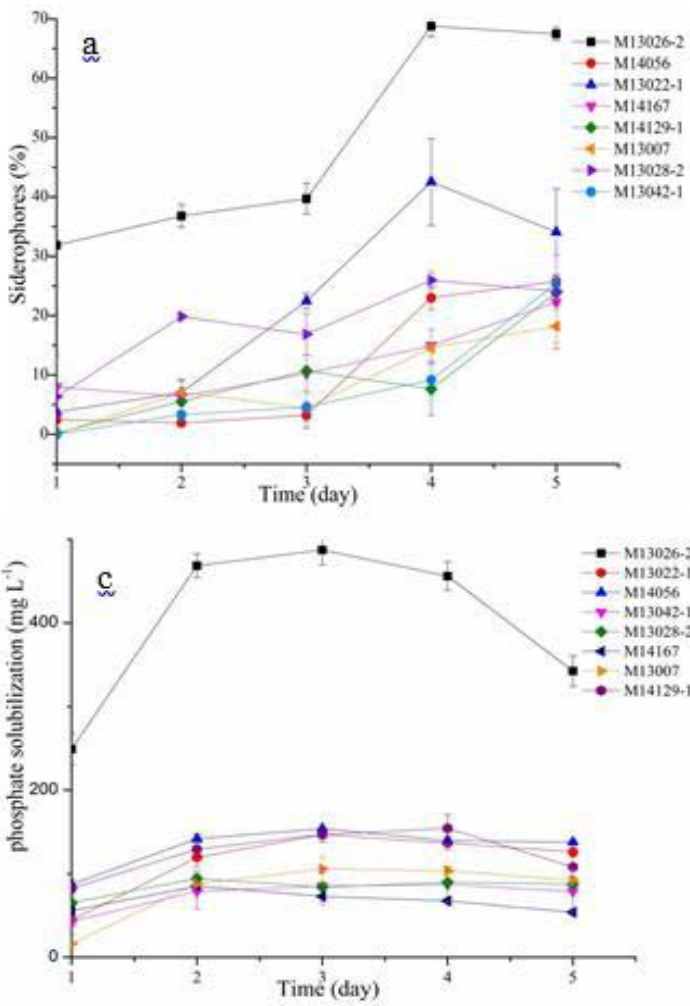

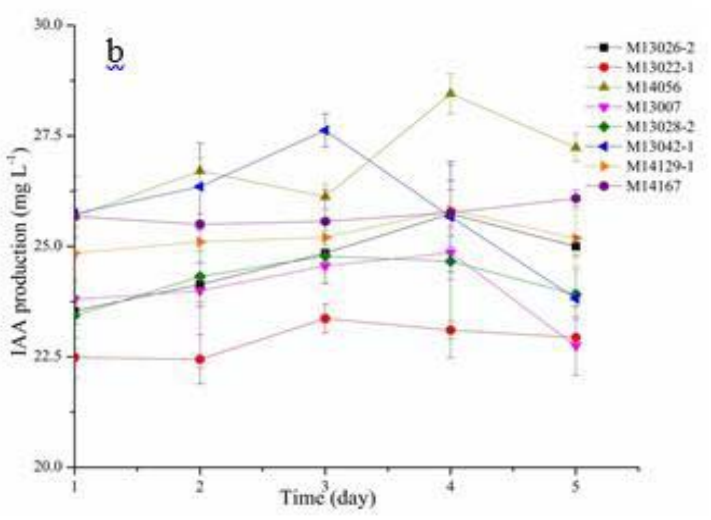

d

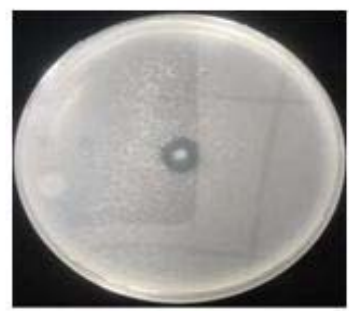

Figure 1: Four biological changes in the fermentation broth of eight strains within a week.

a: Spectrophotometric determination of siderophore production.

b: Spectrophotometric determination of IAA production.

c: Spectrophotometric determination of inorganic phosphorus solubilization.

d: Photograph of phosphate dissolving circle of strain M13026-2 in solid medium containing calcium phytate. The data are from three biological replicates and shown as mean values \pm standard error.

was randomly selected from each tissue and transferred to a new PDA medium for culture, and DNA was extracted and rDNA ITS region was sequenced for verification.

Isolation Frequency $(\%)=($ Total number of root colonized $/$ Total number of roots) $\times 100$

Statistical analyses: All experimental data were statistically analyzed by SPSS 17.0. Analysis of variance (ANOVA) and Duncan's multiplicity test were used for statistical analysis $(\mathrm{p}<0.05)$.

\section{Results and Discussion}

\section{Growth promoting traits of fungi}

All the eight tested fungi showed different degrees of siderophores production, IAA production and phosphorus dissolving ability (Figure 1). The siderophores content of the Talaromyces strain M13026-2 was 67.5\%, which showed 59\% higher than that of the Trichoderma strain M13022-1 (Figure 1a). IAA content of the eight fungi was between 23.4 and $28.5\left(\mathrm{mg} \mathrm{L}^{-1}\right)$, there was no significant difference in IAA content among tested fungi (Figure 1b). The available phosphorus content of eight tested fungi reached the maximum on the third day, and the available phosphorus content of the Talaromyces strain M13026-2 was $490 \mathrm{mg} \mathrm{L}^{-1}$, which was $216 \%$ higher than that of the Trichoderma strain M14129-1 (Figure 1c). Plates experiment showed that the strain M13026-2 had the ability to dissolve organic phosphorus, and a clear ring was observed (Figure 1d), D/d=2.75. After one week of culture, it was found that all the insoluble calcium phytate in the plate was dissolved, while no phosphorus dissolving ring was observed around other Trichoderma strains. Based on the above data, it was found that the Talaromyces strain M13026-2 had the best growth promoting traits, but its IAA yield was little different among the measured strains.

\section{Effects of five fungi on plant growth}

Pot experiments showed that the Talaromyces strain M13026-2 was a plant growth promoting fungus. Compared with the control, the above-ground and underground parts of cucumber seedlings treated with M13026-2 had better phenotypic characteristics (Figure 2). Data analysis showed that all growth parameters of cucumber seedlings treated with M13026-2 were higher than those of the control (Table 1), among which the underground fresh weight, underground dry weight and above-ground fresh weight were significantly higher than those of the control, which increased by $40 \%, 53 \%$ and $19 \%$, respectively. According to the rhizosphere scanner analysis, the root length and root surface area increased by $31 \%$ and $32 \%$ than that of the control group, respectively. Compared with the control, cucumber seedlings treated with M14056 were in the same state with no significant growth promotion effect. From the perspective of underground dry weight, the tested fungi M13022-1, M13042-1, M14129-1 had slight inhibition on the growth of cucumber seedlings. 


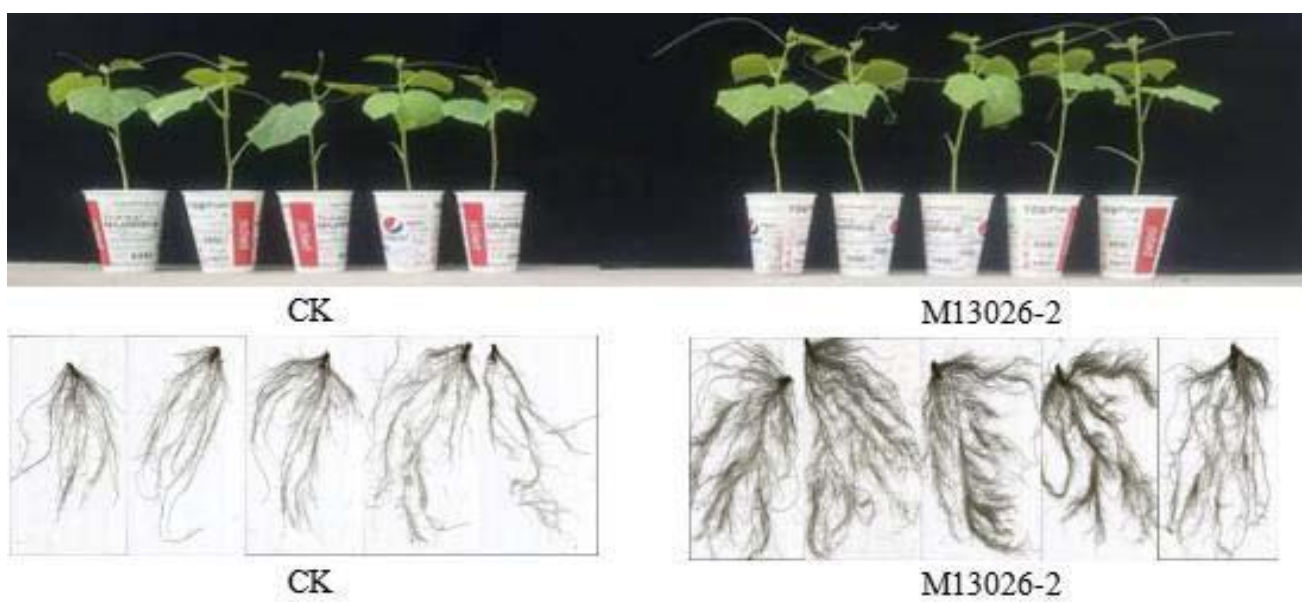

Figure 2: The surface growth state of cucumber seedling treated by strain M13026-2.

Table 1: Effect of soil treated by five strains on growth parameters of cucumber.

\begin{tabular}{|c|c|c|c|c|c|c|c|c|}
\hline $\begin{array}{l}\text { Chlorophy } \\
\text { II }\end{array}$ & $\begin{array}{l}\text { Stem } \\
\text { Diameter } \\
(\mathrm{mm})\end{array}$ & $\begin{array}{l}\text { Plant height } \\
\text { (cm) }\end{array}$ & $\begin{array}{l}\text { Underground } \\
\text { fresh weight }(g)\end{array}$ & $\begin{array}{c}\text { Underground dry } \\
\text { Weight (g) }\end{array}$ & $\begin{array}{c}\text { Above-ground } \\
\text { fresh } \\
\text { Weight (g) }\end{array}$ & $\begin{array}{l}\text { Above-ground dry } \\
\text { Weight (g) }\end{array}$ & $\begin{array}{l}\text { Root } \\
\text { Length } \\
(\mathrm{cm})\end{array}$ & $\begin{array}{c}\text { Root surface area } \\
\left(\mathrm{cm}^{2}\right)\end{array}$ \\
\hline 21.5267 & 3.9933 & 35.5133 & 1.4527 & 0.0783 & 8.906 & 0.7893 & 1192.7687 & 110.1159 \\
\hline $\mathrm{CK} \pm 0.812 \mathrm{a}$ & $\pm 0.134 a$ & $\pm 0.972 \mathrm{a}$ & $\pm 0.125 \mathrm{bc}$ & $\pm 0.006 \mathrm{a}$ & $\pm 0.345 \mathrm{a}$ & $\pm 0.041 \mathrm{a}$ & $\pm 84.365 a$ & $\pm 8.072 \mathrm{a}$ \\
\hline \multirow{2}{*}{$\begin{array}{c}21.7267 \mathrm{M} 13026-2 \pm \\
0.816 \mathrm{a}\end{array}$} & 4.1733 & 37.9867 & 2.0347 & 0.1195 & 10.6107 & 0.8987 & 1566.178 & 145.6904 \\
\hline & $\pm 0.658 \mathrm{a}$ & $\pm 1.592 \mathrm{a}$ & $\pm 0.108 d$ & $\pm 0.006 \mathrm{~b}$ & $\pm 0.29 \mathrm{~b}$ & $\pm 0.058 \mathrm{a}$ & $\pm 53.95 b$ & $\pm 6.701 \mathrm{~b}$ \\
\hline 18.9154 & 4.2695 & 34.2451 & 1.4865 & 0.0756 & 9.4399 & 0.863 & \multirow{2}{*}{-} & \multirow{2}{*}{-} \\
\hline M13022-1 $\pm 0.498 a$ & $\pm 0.26 a$ & $\pm 0.456 \mathrm{a}$ & $\pm 0.234 \mathrm{bc}$ & $\pm 0.003 a$ & $\pm 0.728 a b$ & $\pm 0.13 \mathrm{a}$ & & \\
\hline 19.5183 & 4.2065 & 38.6551 & 0.8473 & 0.075 & 8.8002 & 0.8486 & \multirow{2}{*}{-} & \multirow{2}{*}{-} \\
\hline M13042-1 $\pm 1.001 \mathrm{a}$ & $\pm 0.246 a$ & $\pm 2.026 \mathrm{a}$ & $\pm 0.099 a$ & $\pm 0.001 \mathrm{a}$ & $\pm 0.656 \mathrm{a}$ & $\pm 0.081 \mathrm{a}$ & & \\
\hline 20.0159 & 3.9223 & 32.991 & 1.7539 & 0.0801 & 9.2143 & 0.8721 & \multirow{2}{*}{-} & \multirow{2}{*}{-} \\
\hline M14056 $\pm 0.537 a$ & $\pm 0.086 a$ & $\pm 1.503 a$ & $\pm 0.179 \mathrm{~cd}$ & $\pm 0.001 \mathrm{a}$ & $\pm 0.486 a b$ & $\pm 0.075 \mathrm{a}$ & & \\
\hline 20.664 & 4.0433 & 38.5756 & 1.0798 & 0.0747 & 8.3829 & 0.842 & \multirow{2}{*}{ - } & \multirow{2}{*}{-} \\
\hline M14129-1 $\pm 0.944 a$ & $\pm 0.165 a$ & $\pm 3.031 \mathrm{a}$ & $\pm 0.12 \mathrm{ab}$ & $\pm 0.001 \mathrm{a}$ & $\pm 0.713 a$ & $\pm 0.056 a$ & & \\
\hline
\end{tabular}

Values having the same letter did not differ significantly in the same column $(P<0.05)$. The data are from three biological replicates and shown as mean values \pm standard error.

\section{Identification of PGPF M13026-2}

After incubation for $5 \mathrm{~d}$ at $28^{\circ} \mathrm{C}$, the colony diameter of M130262 on PDA plate was $19 \mathrm{~mm}$, and a large number of spores were produced (Figure $3 \mathrm{a}$ ). Red pigment was produced in the middle of the colony (Figure $3 \mathrm{~b})$. The top of the conidiophores was shaped like a broom (Figure 3c). Conidia were ellipsoidal or subglobose (Figure $3 \mathrm{~d})$. The blast results of rDNA ITS, TUB and CaM gene sequencing of strain M13026-2 showed 100\% homology with the sequences of Talaromyces purpureogenus in GenBank. The results showed that the TUB gene could fully indicate the relationship between the M130262 strain and other related Talaromyces species. On the phylogenetic tree, the strain M13026-2 and the type strain of the species $T$. purpureogenus, CBS 286.36 are in the same clade with $100 \%$ bootstrap value support (Figure 4). Thus, strain M13026-2 was identified as Talaromyce purpureogenus.

\section{Colonization of PGPF M13026-2 in cucumber rhizosphere} soil and tissues

The results of gradient dilution showed that the colonization amount of PGPF M13026-2 in cucumber rhizosphere soil reached the maximum value and remained stable in the fourth week (Figure $5 a)$. Tissue isolation culture found that the isolation frequency of PGPF M13026-2 in cucumber root and stem was $24.72 \%$ and $5.01 \%$, respectively (Figure $5 b$ ), but it could not be isolated from the leaves. In addition, the fungus was not isolated from the control group.

Previous studies suggested that chelates of microbial siderophores and iron ions can be absorbed directly by plants [36]. Adding a strain of Trichoderma asperellum with high siderophores yield to the soil significantly increased the level of iron ions in the soil [37]. It has been reported that Aspergillus tubingensis has biocontrol and growth promoting functions on tomatoes, and the content of siderophores and IAA in liquid medium of this fungus is $61.5 \%$ and $6 \mathrm{mg} \mathrm{L}^{-1}$ [38], respectively. In this study, Talaromyces purpureogenus as PGPF had the highest siderophores content of $67.5 \%$. Among Trichoderma strains, M13022-1 had the highest content of siderophores and the highest value was $42.5 \%$, which had no promoting effect on cucumber seedlings. Maybe, when screening a large number of fungal resources 

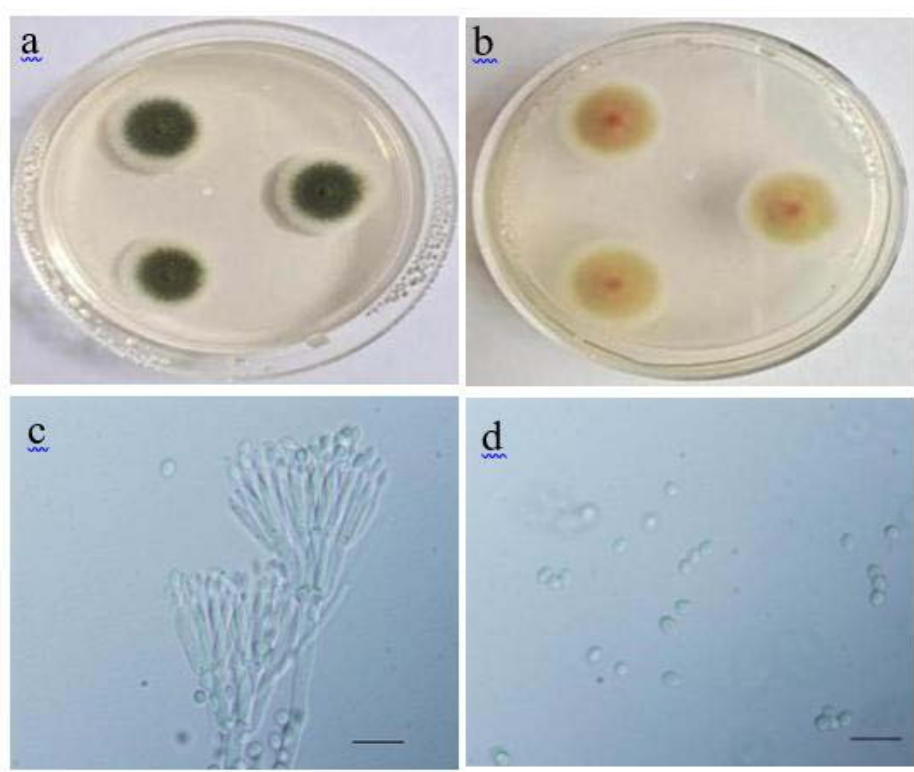

Figure 3: Morphological characteristics of strain M13026-2.

a: Front features of M13026-2 colony.

b: Back features of M13026-2 colony.

c: Conidiophores.

d: Conidi. Bar=10 $\mu \mathrm{m}$.

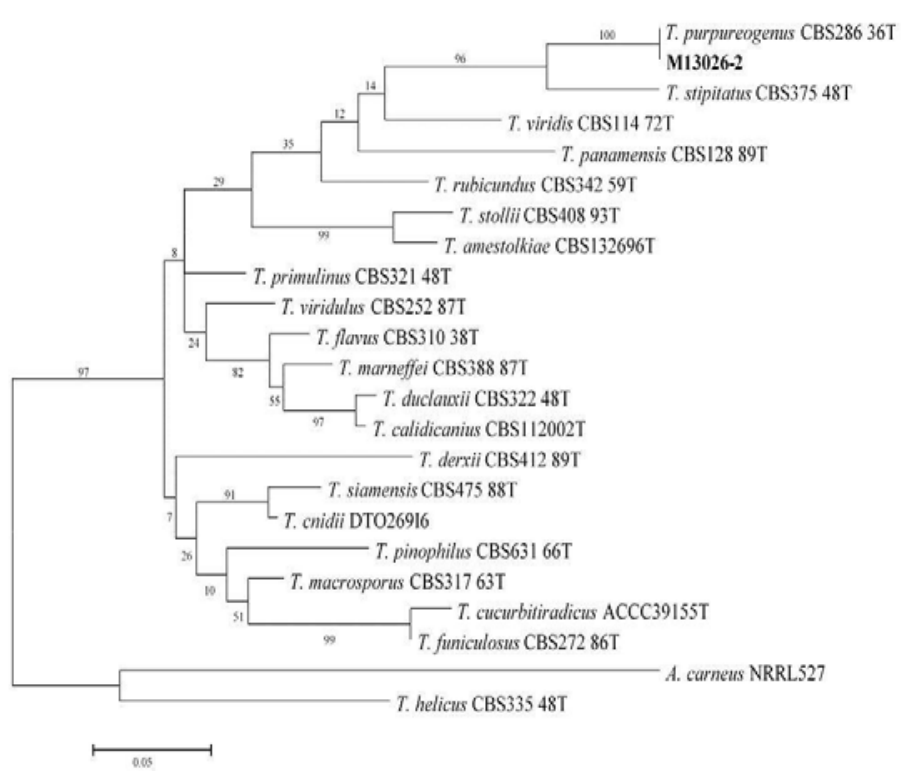

Figure 4: Phylogenetic analysis of the BUT sequences from strain M13026-2 and Talaromyces.

with the potential to promote plant growth, the fungal resources with siderophores content of about $67.5 \%$ should be focused on.

IAA was also beneficial to the colonization of Aspergillus awamori in maize roots and promoted plant growth, playing an important role in the interaction between microorganisms and plants [39]. It has been reported that three main fungi have been isolated from the rhizosphere soil of peanut, among which a Penicillium strain with high IAA production capacity $\left(272 \mathrm{mgL}^{-1}\right)$ have more obvious growth promoting effect on plants [40], in our study, the IAA content of Talaromyces purpureogenus fermentation broth was much lower than that of the Penicillium strain, but Talaromyces purpureogenus M13026-2 also has the ability to promote plant growth. In addition, although the five tested fungi of Trichoderma in this study did not show the ability to promote plant growth in pot experiment, but the IAA production capacity of the above Trichoderma strains was higher than that of Trichoderma harzianum $\left(14.2 \mathrm{mgL}^{-1}\right)$, which had promoting effect on plants [41]. Therefore, in this study, the IAA production capacity of the five fungi tested in pot experiment showed no related to their ability to promote plant growth. However, 

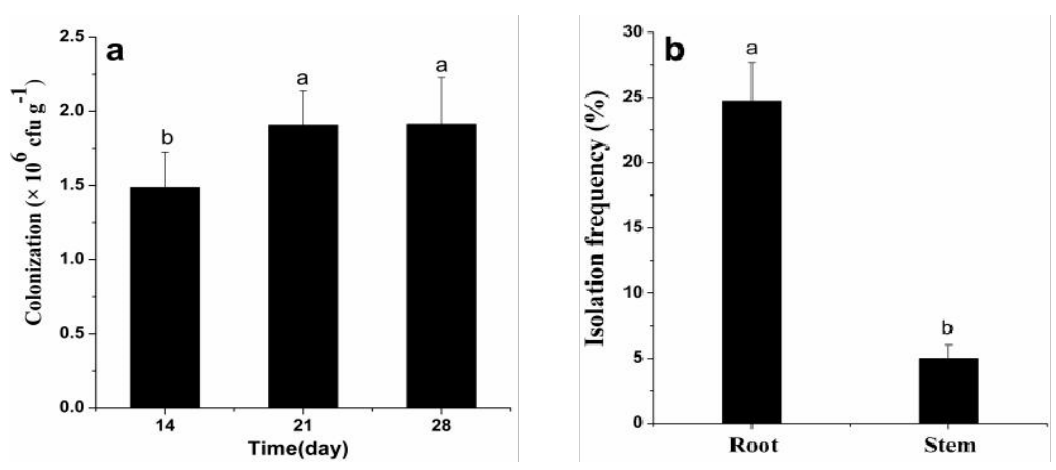

Figure 5: Colonization ability of Talaromyces purpureogenus

a: The colonization amount in rhizosphere soil.

b: The isolation frequency in cucumber tissue. Values having the same letter did not differ significantly $(P<0.05)$. The data are from three biological replicates and shown as mean values \pm standard error.

cucumber was selected as the plant to be tested and the use of natural farmland soil for the experiment in this study maybe affect the results.

Phosphorus is the limiting factor of crop yield [42]. Studies have shown that PGPF Talaromyces flavus can increase the uptake and utilization of available phosphorus by plants [11], the acid phosphatase secreted by Trichoderma asperellum under salt stress can promote the growth of Arabidopsis thaliana [43]. In this experiment, the PGPF Talaromyces purpureogenus M13026-2 has strong ability of dissolving organic phosphorus and inorganic phosphorus, there is a strong contrast with the tested Trichoderma fungi. Therefore, there is a certain correlation between the phosphate dissolving traits of fungi and the ability of promoting plant growth, which can be used as one of the bases for screening beneficial fungi.

Studies have shown that T. purpureogenus is widely distributed and has good antibacterial activity, and its liquid metabolites can inhibit many pathogenic bacteria [44]. T. purpureogenus CFRM02 pigment has biological safety and is recommended to be used in food and nutraceuticals [45]. After soil fumigation, T. purpureogenus can enrich a variety of beneficial microorganisms and inhibit the growth of Fusarium oxysporum, so as to improve the biocontrol effect of bitter gourd Fusarium wilt [46]. To our knowledge, studies on T. purpureogenus in promoting plant growth have not been reported. This study found that T. purpureogenus had the most obvious effect on the growth of plant roots, forming a mutualistic relationship. In our experimental period, M13026-2 could be effectively colonized in rhizosphere soil of cucumber seedlings and became the dominant species in rhizosphere fungi community, suggesting that the strain had certain fecundity in rhizosphere soil.

\section{Conclusion}

Based on the above findings, we concluded that the correlation between phosphate dissolving capacity and plant growth promoting potential of fungi was the highest, followed by the ability to produce siderophores. Talaromyces purpureogenus M13026-2 with strong growth promoting traits had plant growth promoting effect, and could colonize stably in cucumber rhizosphere soil and tissues. In terms of phylogenetic analysis of rDNA ITS, TUB and CaM genes, TUB gene can better be used to T. purpureogenus to differentiate itself from other close species of the genus Talaromyces. These findings reveal the potential of widely using $T$. purpureogenus to promote the green development of agriculture.

\section{References}

1. Huang G, Wang X, Qian H, Zhao T, Zhao Q. Negative impact of inorganic fertilizes application on agricultural environment and its countermeasures. Ecology Env. 2004; 13: 656-660.

2. Raza W, Shen Q. Growth, $\mathrm{Fe}^{3+}$ reductase activity, and siderophore production by Paenibacillus polymyxa SQR-21 under differential iron conditions. Curr Microbiol. 2010; 61: 390-395.

3. Segarra G, Casanova E, Avilés M, Trillas I. Trichoderma asperellum strain T34 controls Fusarium wilt disease in tomato plants in soilless culture through competition for iron. Microb Ecol. 2010; 59: 141-149.

4. Qi W, Zhao L. Study of the siderophore-producing Trichoderma asperellum Q1 on cucumber growth promotion under salt stress. J Basic Microbiol. 2013; 53: 355-364.

5. Zhao L, Wang Y, Kong S. Effects of Trichoderma asperellum and its siderophores on endogenous auxin in Arabidopsis thaliana under irondeficiency stress. Int Microbiol. 2020; 23: 501-509.

6. Della Mónica IF, Godeas AM, Scervino JM. In Vivo Modulation of Arbuscular Mycorrhizal Symbiosis and Soil Quality by Fungal P Solubilizers. Microb Ecol. 2020; 79: 21-29.

7. Zhong C, Cao G, Huang W, Luan XS, Yang YF. Dissolving mechanism of strain P17 on insoluble phosphorus of yellow-brown soil. Braz J Microbiol. 2014; 45: 937-943.

8. Yin Z, Shi F, Jiang H, Roberts DP, Chen SF, Fan BQ. Phosphate solubilization and promotion of maize growth by Penicillium oxalicum P4 and Aspergillus niger P85 in a calcareous soil. Can J Microbiol. 2015; 61: 913-923.

9. Vassilev N, Vassileva M, Nikolaeva I. Simultaneous P-solubilizing and biocontrol activity of microorganisms: potentials and future trends. Appl Microbiol Biotechnol. 2006; 71: 137-144.

10. Zhao L, Liu Q, Zhang Y, Cui Q, Liang Y. Effect of acid phosphatase produced by Trichoderma asperellum Q1 on growth of Arabidopsis under salt stress. J Integr Agr. 2017; 16: 1341-1346.

11. Della Mónica IF, Godoy MS, Godeas AM, Scervino JM. Fungal extracellular phosphatases: their role in $\mathrm{P}$ cycling under different $\mathrm{pH}$ and $\mathrm{P}$ sources availability. J Appl Microbiol. 2018; 124: 155-156.

12. Naraghi L, Heydari A, Rezaee S, Razavi M. Biocontrol Agent Talaromyces flavus Stimulates the Growth of Cotton and Potato. J Plant Growth Regul. 2012; 31: 471-477.

13. Naraghi L, Heydari A, Rezaee S, Razavi M, Afshari-Azad H. Promotion of growth characteristics in greenhouse cucumber and tomato by Talaromyces flavus. Intl J Agri Res. 2012; 2: 116-128. 
14. Mahdizadehnaraghi R, Heydari A, Zamanizadeh HR, Rezaee S, Nikan J. Promotion of garlic growth characteristics using bioformulations developed based on antagonistic fungi. Intl J Agri Crop Sci. 2015; 8: 654-658.

15. Yamagiwa $Y$, Inagaki $Y$, Ichinose $Y$, Toyoda $K$, Hyakumachi M, Shiraishi T Talaromyces wortmannii FS2 emits $\beta$-caryphyllene, which promotes plan growth and induces resistance. J Gen Plant Pathol. 2011; 77: 336-341.

16. Akter Z, Weinmann M, Neumann G, Römheld V. An in-vitro screening method to study the activity potential of biofertilizers based on Trichoderma and Bacillus sp. J Plant Nutr. 2013; 36: 1439-1452.

17. Gu XL, Chen W, Cai F. Effect of Trichoderma biofertilizer on continuous cropping cucumber cultivation with reduced rates of chemical fertilizer application. Acta Pedologica Sinica. 2016; 53: 1296-1305.

18. Avis TJ, Gravel V, Antoun H, Tweddell RJ. Multifaceted Beneficial effects of rhizosphere microorganisms on plant Health and productivity. Soil Bio Biochem. 2008; 40: 1733-1740.

19. Babu AG, Kim SW, Yadav R, Hyum U, Lee YS. Penicillium menonorum: A Novel Fungus to Promote Growth and Nutrient Management in Cucumber Plants. Mycobiology. 2015; 43: 49-56.

20. Kotasthane A, Agrawal T, Kushwah R, Rahatkar OV. In-vitro antagonism of Trichoderma spp. against Sclerotium rolfsii and Rhizoctonia solani and their response towards growth of cucumber, bottle gourd and bitter gourd. Eur J Plant Pathol. 2015; 141: 523-543.

21. Marín-Guirao JI, Rodríguez-Romera P, Lupión-Rodríguez B, Camacho-ferre F, Tello-Marquina JC. Effect of Trichoderma on horticultural seedlings growth promotion depending on inoculum and substrate type. J Appl Microbiol. 2016; 121: 1095-1102.

22. Schwyn B, Neilands JB. Universal chemical assay for the detection and determination of siderophores. Anal Biochem. 1987; 160: 47-56.

23. Machuca A, Milagres AMF. Use of CAS-agar plate modified to study the effect of different variables on the siderophore production by Aspergillus. Let Appl Microbiol. 2003; 36: 177-181

24. Glickmann E, Dessaux Y. A critical examination of the specificity of the Salkowski reagent for indolic compounds produced by phytopathogenic bacteria. Appl Environ Microbiol. 1995; 61: 793-796.

25. Jackson ML. Soil Chemical Analysis. Prentice Hall, New Delhi. 1973.

26. Yu XM, Wang Y, Shen QB, Li BL, He CP, Zheng FC. The Screening of Phosphorus Solubilizing Bacteria PSB3 and the Study of Its Antagonism. Microbiology. 2008; 35: 1398-1403.

27. Hoyos-Carvajal L, Orduz S, Bissett J. Growth stimulation in bean (Phaseolus vulgaris L.) by Trichoderma. Biocontrol. 2009; 51: 409-416.

28. Yuan SF, Li MY, Fang ZY, Liu Y, Shi W, Pan B, et al. Biological control of tobacco bacterial wilt using Trichoderma harzianum amended bioorganic fertilizer and the arbuscular mycorrhizal fungi Glomus mosseae. Biol Control. 2016; 92: 164-171

29. White TJ, Bruns T, Lee S, Taylor JW. Amplification and direct sequencing of fungal ribosomal RNA genes for phylogenetics. Editors. In: Innis MA Gelfand DH, Sninsky JJ, White TJ. PCR protocols: a guide to the methods and applications. New York: Academic Press. 1990; 315-322.

30. Glass NL, Donaldson G. Development of primer sets designed for use with the PCR to amplify conserved genes from filamentous Ascomycetes. App Environ Microbiol. 1995; 61: 1323-1330.
31. Wang L. Four new records of Aspergillus sect. Usti from Shandong Province, China. Mycotaxon. 2012; 120: 373-384.

32. Su L, Niu Y. Multilocus phylogenetic analysis of Talaromyces species isolated from cucurbit plants in China and description of two new species, $T$. cucurbitiradicus and T. endophyticus. Mycologia. 2018; 110: 375-386.

33. Tian Y, Gao L. Bacterial Diversity in the Rhizosphere of Cucumbers Grown in Soils Covering a Wide Range of Cucumber Cropping Histories and Environmental Conditions. Microb Ecol. 2014; 68: 794-806.

34. Hossain MM, Sultana F, Kubota M, Hyakumachi M. Differential inducible defense mechanisms against bacterial speck pathogen in Arabidopsis thaliana by plant-growth-promoting-fungus Penicillium sp. GP16-2 and its cell free filtrate. Plant Soil. 2008; 304: 227-239.

35. Sun X, Ding Q, Hyde KD, Guo LD. Community structure and preference of endophytic fungi of three woody plants in a mixed forest. Fungal Ecol. 2012; 5: 624-632.

36. Chen L, Dick WA, Streeter JG. Production of aerobactin by microorganisms from a compost enrichment culture and soybean utilization. J Plant Nutr. 2000; 23: 2047-2060.

37. Zhao L, Wang F, Zhang Y, Zhang J. Involvement of Trichoderma asperellum strain T6 in regulating iron acquisition in plants. J Basic Microbiol. 2014; 54 : S115-S124.

38. Zhao J, Liu W, Liu D, Lu C, Zhang D, Wu H, et al. Identification and evaluation of Aspergillus tubingensis as a potential biocontrol agent against grey mould on tomato. J Gen Plant Pathol. 2018; 84: 148-159.

39. Mehmood A, Hussain A, Irshad M, Hamayun M, Iqbal A, Khan N. In vitro production of IAA by endophytic fungus Aspergillus awamori and its growth promoting activities in Zea mays. Symbiosis. 2018; 77: 225-235

40. Radhakrishnan R, Shim KB, Lee BW. IAA-producing Penicillium sp. NICS01 triggers plant growth and suppresses Fusarium sp.-induced oxidative stress in sesame (Sesamum indicum L.). J Microbiol Biotechnol. 2013; 23: 856-863.

41. Zhang F, Yuan J, Yang X, Cui Y, Chen L, Ran W, et al. Putative Trichoderma harzianum mutant promotes cucumber growth by enhanced production of indole acetic acid and plant colonization. Plant Soil. 2013; 368: 433-444

42. Shen JB, Yuan LX, Zhang JL, Li HG, Bai ZH, Chen XP, et al. Phosphorus dynamics: from soil to plant. lant Physiol. 2011; 156: 997-1005.

43. Zhao L, Zhang YQ. Effects of phosphate solubilization and phytohormone production of Trichoderma asperellum Q1 on promoting cucumber growth under salt stress. J Integr Agric. 2015; 14: 1588-1597.

44. Sobral LV, Melo KN, Souza CM, Silva SF, Silva GLR, Silva ALF, et al. Antimicrobial and enzymatic activity of anemophilous fungi of a public university in Brazil. An Acad Bras Cienc. 2017; 89: 2327-2340.

45. Pandit SG, Puttananjaiah MH, Peddha MS, Dhale MA. Safety efficacy and chemical profiling of water-soluble Talaromyces purpureogenus CFRM02 pigment. Food Chem. 2019; 310: 125869.

46. Tian YH, Peng HY, Wang DH, Li XF, He BL, Gao KX. Biocontrol potential of Talaromyces purpurogenus and its regulation on soil microbial community. Chin J Appl Ecol. 2020; 31: 3255-3266. 